\title{
Influence of grinding parameters on the surface roughness of steel 1.0562 in the softened state
}

\author{
Wpływ parametrów szlifowania na chropowatość \\ powierzchni stali $1.0562 \mathrm{w}$ stanie zmiękczonym
}

\author{
MARIUSZ DEJA \\ PIOTR WASZCZUR \\ KAROLINA WSZELAK *
}

DOI: https://doi.org/10.17814/mechanik.2017.11.164

Results from testing the grinding process of structural elements made of alloy steel 1.0562 in the softened state are presented. Influence of the grinding depth $a_{e}$ and the longitudinal feedrate of the workpiece $v_{f t}$ on the surface roughness is analyzed. Roughness values of $R a, R z$ and $R t$ were considered available to obtain under accepted test conditions. KEYWORDS: surface grinding, feed speed, depth of grinding, surface roughness parameters

The correct course of the grinding process is related to the appropriate selection of technological parameters, which allows to meet certain construction requirements, mainly to obtain high dimensional accuracy and shape of the required surface geometry (WW) and achieve the desired condition of the workpiece (PO) $[2,5]$. In addition to the low surface roughness and high grinding efficiency [1], the research also reduces the process energy consumption and carbon dioxide emissions [6]. The grinding wheel and its conditioning parameters also have a significant influence on the process and technological effects [3]. Proper selection of machining parameters with correct delivery of cooling-lubricating fluid (CCS) avoids damage in the form of micro-cracks and cures in WW-PO [4] and prolongs the service life of the workpieces, e.g. railway rails [5].

The results of the study along with the assessment of the effect of grinding depth $a_{e}$ and the longitudinal feedrate of the object $v_{\mathrm{ft}}$ on the values of surface roughness parameters of structural elements made of 1.0562 steel in the softened state, were presented. Obtaining Ra roughness value below $0.1 \mu \mathrm{m}$ was one of the basic design requirements for plates (fig. 1), which is a research hydraulic device.

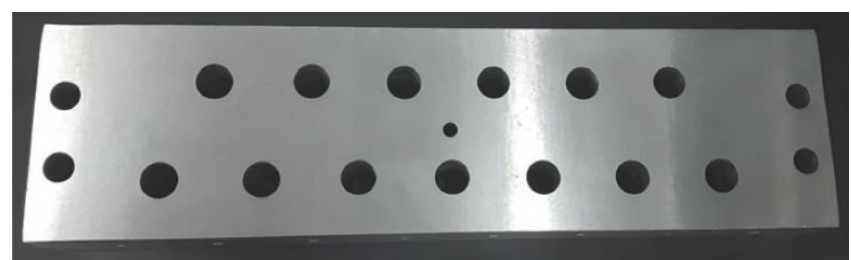

Fig. 1. Plate with holes after grinding

\footnotetext{
* Dr hab. inż. Mariusz Deja (mariusz.deja@pg.edu.pl), dr inż. Piotr Waszczur (piotr.waszczur@pg.edu.pl), mgr inż. Karolina Wszelak (karolina. wszelak@pg.edu.pl)-Katedra Technologii Maszyn i Automatyzacji Produkcji, Wydział Mechaniczny Politechniki Gdańskiej
}

\section{Test conditions}

Grinding tests were performed on a CNC grinding machine for SPG 25X60 planes with horizontal spindle axis. The panels of $256 \times 68 \times 28 \mathrm{~mm}$ dimensions (fig. 1 ) made of 1.0562 steel with hardness of $220 \mathrm{HB}$, tensile strength $R m=$ $490 \div 630 \mathrm{MPa}$ and yield strength $R e=335 \mathrm{MPa}$, were machined. By default, the components of this material are heat treated to increase their hardness and wear resistance. In the research carried out for the purpose of the hydraulic equipment, in accordance with the requirements of the constructor, the plates were softened. The treatment was carried out with Norton Grinding Wheels at 38A60LVS and dimensions $(D \times T \times H) 250 \times 25 \times 76.2 \mathrm{~mm}$.

The grinding was performed at constant wheel circumferential speed $v_{s}=25 \mathrm{~m} / \mathrm{s}$, using coolant. The transverse feedrate of the grinding wheel followed the grinding wheel along the grinding surface and was $15 \mathrm{~mm}$ (60\% of the grinding wheel). Prior to each test, the grinding wheel was conditioned with a diamond dresser with the following parameters set in the control program:

- depth $a_{e}$ at one passage $-0.01 \mathrm{~mm}$,

- number of crossing passages - 4,

- abrasive wheel circumferential velocity $-v_{s}=23 \mathrm{~m} / \mathrm{s}$,

- transverse feedrate of abrasive wheel $-f_{a}=0.2 \mathrm{~mm} / \mathrm{rev}$.

\section{TABLE I. Grinding parameters}

\begin{tabular}{|c|c|c|c|c|}
\hline \multirow{2}{*}{$\begin{array}{l}\text { Number } \\
\text { of } \\
\text { sample }\end{array}$} & \multicolumn{2}{|c|}{$\begin{array}{l}\text { Levels of initial } \\
\text { parameters }\end{array}$} & \multicolumn{2}{|c|}{ Values of parameters } \\
\hline & $\begin{array}{c}\text { Feedrate } \\
v_{\mathrm{ft}}\end{array}$ & $\begin{array}{l}\text { Grinding } \\
\text { depth } a_{e}\end{array}$ & $\begin{array}{c}V_{\mathrm{ft}} \\
\mathrm{m} / \mathrm{min}\end{array}$ & $\begin{array}{c}a_{\mathrm{e}} \\
\mathrm{mm}\end{array}$ \\
\hline 1 & 1 & 1 & 0.3 & 0.002 \\
\hline 2 & 1 & 2 & 0.3 & 0.004 \\
\hline 3 & 1 & 3 & 0.3 & 0.006 \\
\hline 4 & 2 & 1 & 0.9 & 0.002 \\
\hline 5 & 2 & 2 & 0.9 & 0.004 \\
\hline 6 & 2 & 3 & 0.9 & 0.006 \\
\hline 7 & 3 & 1 & 1.8 & 0.002 \\
\hline 8 & 3 & 2 & 1.8 & 0.004 \\
\hline 9 & 3 & 3 & 1.8 & 0.006 \\
\hline
\end{tabular}

Statistically determined complete 3-value study plan PS/DK-32 was adopted. Each grinding test (Table I) was repeated.

Less velocity of the longitudinal feedrate $v_{\mathrm{ft}}$ than the recommended ones [2] was assumed, because at higher velocities, the roughness and the waviness of the surface of the PO increased with visible inequalities in the form of bands. After each grinding and repetition test, 4 surface 
roughness measurements were taken - a total of 8 measurements. For this purpose, the contact profilometer HOMMEL TESTER T1000 was used. Measurements were made for an elementary section of $0.8 \mathrm{~mm}$.

\section{Test results}

Fig. 2 and fig. 3 show mean values of roughness parameters from individual grinding tests (Table I), and as a measure of spread, the standard deviation was assumed. The highest values of roughness parameters, irrespective of the grinding depth, were obtained after samples 7-9 with the highest feedrate of $v_{\mathrm{ft}}=1.8 \mathrm{~m} / \mathrm{min}$. The lowest - values of roughness parameters such as $R a, R z$ and $R t$ were obtained after grinding with $v_{\mathrm{ft}}=0.9 \mathrm{~m} / \mathrm{min}$ and $a_{\mathrm{e}}=0.004 \mathrm{~mm}$.

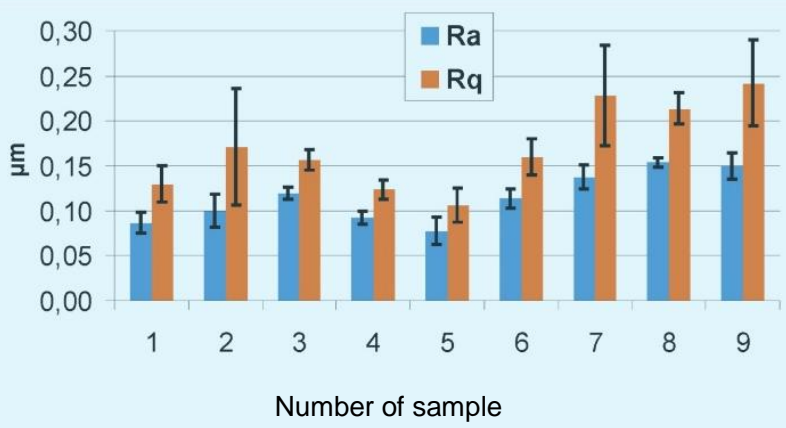

Fig. 2. Average values of surface roughness parameters $R a$ and $R q$ obtained after subsequent grinding tests

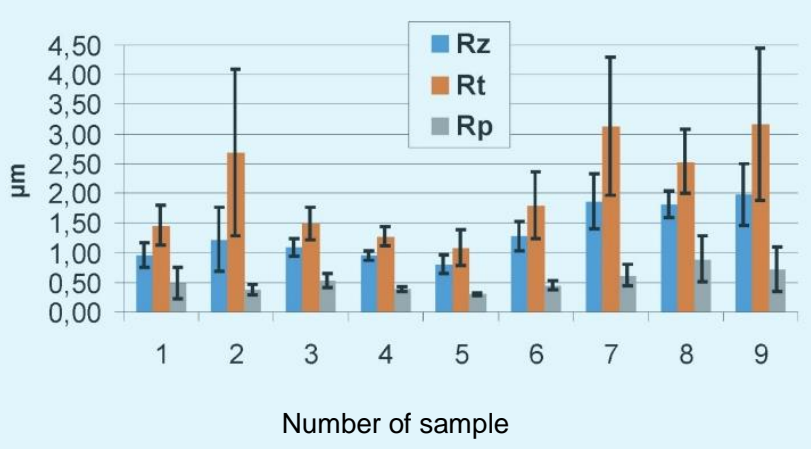

Fig. 3. Average values of surface roughness parameters $R z, R t$ and $R p$ obtained after subsequent grinding tests

TABLE II. ANOVA analysis for parameter $R \boldsymbol{R}$

\begin{tabular}{|c|c|c|c|c|c|c|}
\hline $\begin{array}{c}\text { Variance } \\
\text { source }\end{array}$ & SS & $d f$ & $M S$ & $F$ & $p$ & $F$ test \\
\hline$v_{\mathrm{ft}}$ & 0.038 & 2 & 0.019 & 129.805 & 0.000 & 3.143 \\
\hline$a_{\mathrm{e}}$ & 0.007 & 2 & 0.003 & 23.804 & 0.000 & 3.143 \\
\hline$v_{\mathrm{ft}} \cdot a_{\mathrm{e}}$ & 0.005 & 4 & 0.001 & 8.297 & 0.000 & 2.518 \\
\hline Error & 0.009 & 63 & 0.000 & & & \\
\hline Total & 0.05875 & 71 & & & & \\
\hline \multicolumn{7}{|c|}{$\begin{array}{l}\text { Legend: } S S-\text { sum of squares of deviations; } d f-\text { number of } \\
\text { degrees of freedom; } M S-\text { average square of deviations; } F- \\
\text { calculated value of } F \text { statistics; } p-\text { probability; } F \text { test - critical } \\
\text { value read at significance level } \alpha=0.05 \text {. }\end{array}$} \\
\hline
\end{tabular}

TABLE III. ANOVA analysis for parameter $\boldsymbol{R t}$

\begin{tabular}{|c|c|c|c|c|c|c|}
\hline $\begin{array}{c}\text { Variance } \\
\text { source }\end{array}$ & $S S$ & $d f$ & $M S$ & $F$ & $p$ & $F$ test \\
\hline$v_{\mathrm{tt}}$ & 33.952 & 2 & 16.976 & 19.754 & 0.000 & 3.143 \\
\hline$a_{\mathrm{e}}$ & 0.623 & 2 & 0.311 & 0.362 & 0.697 & 3.143 \\
\hline$v_{\mathrm{tt}} \cdot a_{\mathrm{e}}$ & 15.352 & 4 & 3.838 & 4.466 & 0.003 & 2.518 \\
\hline Error & 54.140 & 63 & 0.859 & & & \\
\hline Total & 104.066 & 71 & & & & \\
\hline
\end{tabular}

TABLE IV. ANOVA analysis for parameter $R z$

\begin{tabular}{|c|c|c|c|c|c|c|}
\hline $\begin{array}{c}\text { Variance } \\
\text { source }\end{array}$ & $S S$ & $d f$ & $M S$ & $F$ & $p$ & $F$ test \\
\hline$v_{\text {tt }}$ & 12.871 & 2 & 6.435 & 58.958 & 0.000 & 3.143 \\
\hline$a_{\mathrm{e}}$ & 0.543 & 2 & 0.272 & 2.489 & 0.091 & 3.143 \\
\hline$v_{\text {tt }} \cdot a_{\mathrm{e}}$ & 1.147 & 4 & 0.287 & 2.628 & 0.043 & 2.518 \\
\hline Error & 6.877 & 63 & 0.109 & & & \\
\hline Total & 21.438 & 71 & & & & \\
\hline
\end{tabular}

Tables II-IV present results of the study upon significance of the influence of grinding parameters on surface roughness parameters. The analysis was performed for assumed significance level $\alpha=0.05$.

In the case of the roughness parameter $R a$, the $v_{\mathrm{ft}}$ and $a_{e}$ parameters as well as interaction between them were significantly affected. The parameter $R t$ was most influenced by velocity of the longitudinal feedrate of the object $v_{\mathrm{ft}}$ and interaction of this parameter with the grinding depth $a_{\mathrm{e}}$. Similar results were obtained for $R z$ parameter.

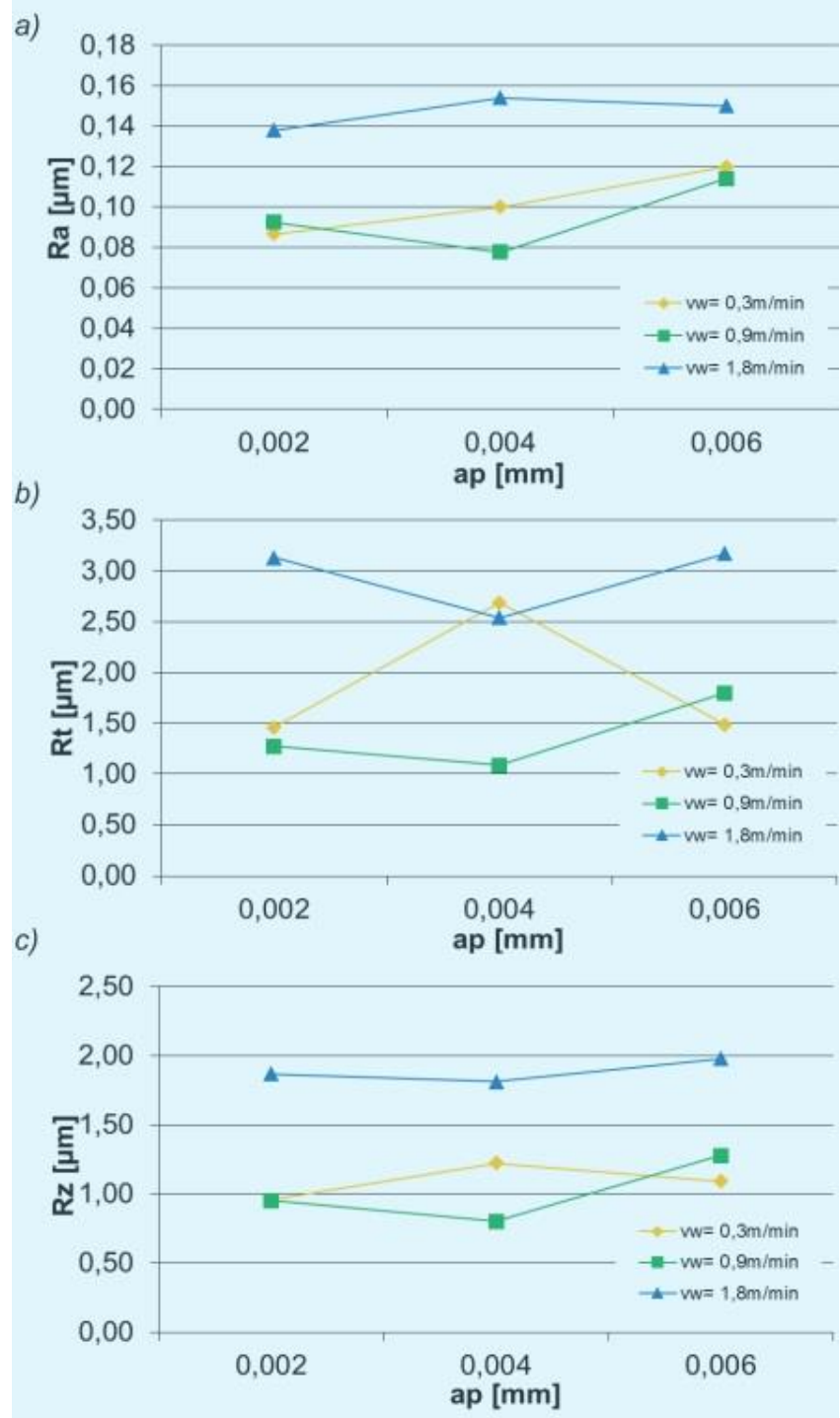

Fig. 4. Dependence of roughness parameters: a) $R a$, b) $R t$, c) $R z$ for ground surface on the longitudinal feedrate $v_{t t}$ and grinding depth $a_{e}$

Fig. 4 shows the values of roughness parameters $R a, R t$ and $R z$ obtained depending on the feedrate of the object and the depth of grinding. It can be seen that within the range of assumed values of $v_{\mathrm{ft}}=0.3$ and $0.9 \mathrm{~m} / \mathrm{min}$, the $R a$ and $R z$ values were similarly independent of the grinding depth. Only for $R t$, significant values were recorded for the smallest longitudinal feedrate of the object $v_{\mathrm{ft}}$ and grinding depth $a_{\mathrm{e}}=$ $0.004 \mathrm{~mm}$. 
Exemplary roughness profiles with material contribution curves and ordinate distributions are illustrated in figs. 5-7.

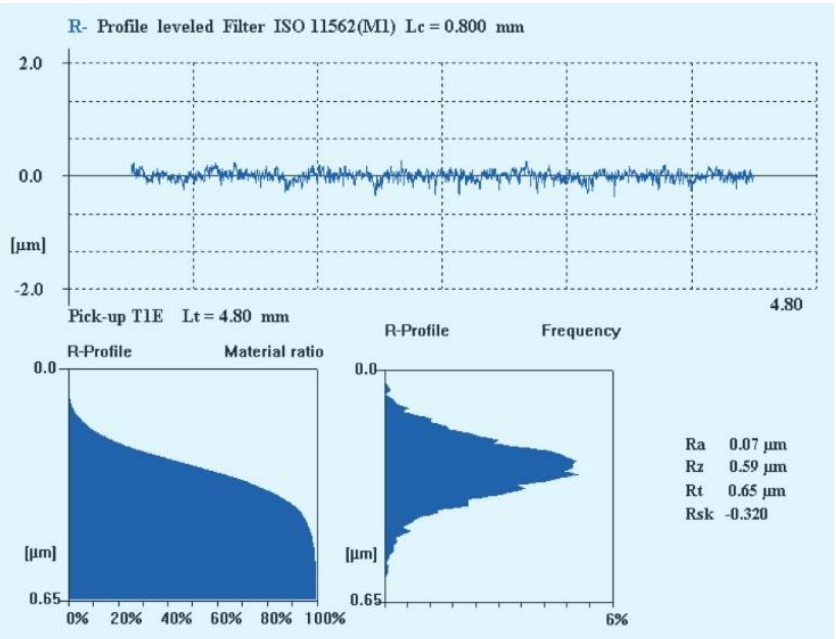

Fig. 5. Exemplary surface roughness profile obtained after grinding with parameters $v_{\mathrm{tt}}=0.9 \mathrm{~m} / \mathrm{min}$ and $a_{\mathrm{e}}=0.004 \mathrm{~mm}$

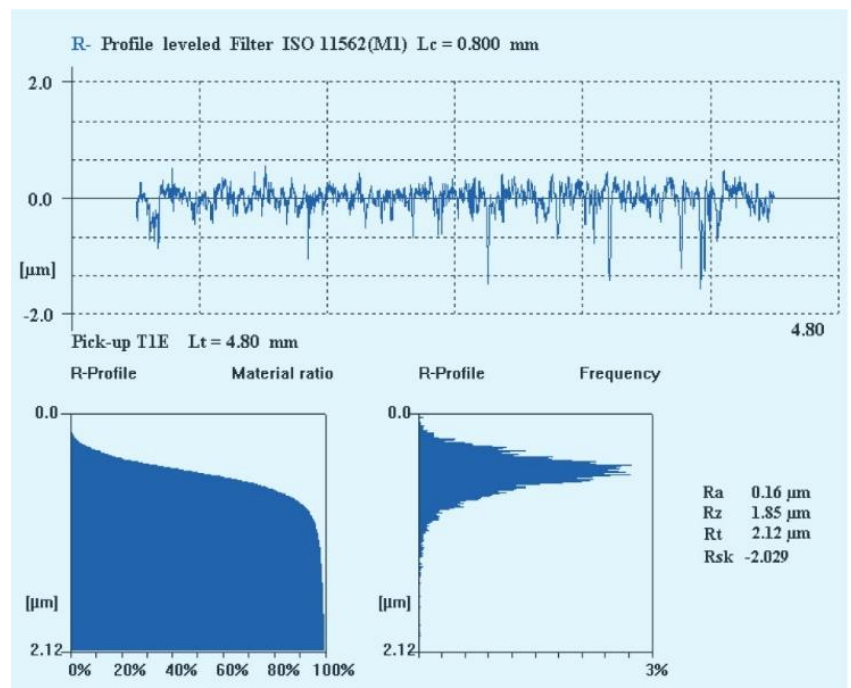

Fig. 6. Exemplary surface roughness profile obtained after grinding with parameters $v_{\mathrm{tt}}=1.8 \mathrm{~m} / \mathrm{min}$ and $a_{\mathrm{e}}=0.006 \mathrm{~mm}$

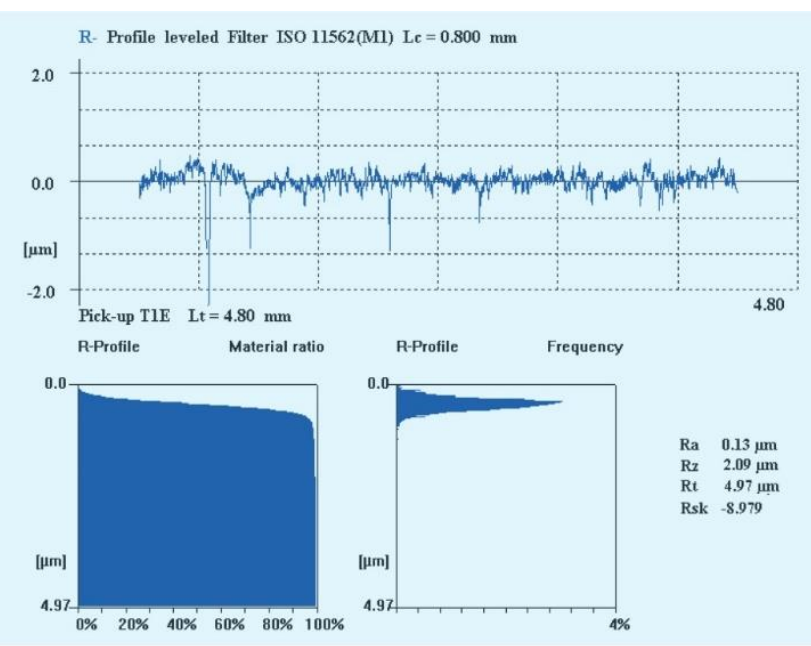

Fig. 7. Exemplary surface roughness profile obtained after grinding with parameters $v_{\mathrm{tt}}=0.3 \mathrm{~m} / \mathrm{min}$ and $a_{\mathrm{e}}=0.004 \mathrm{~mm}$

The most favorable surfaces were obtained after grinding the sample No. 5. An example of such surface area is shown in fig. 5. The surface profile after grinding with the highest values of parameters (sample No. 9) is shown in fig. 6 . When comparing the profiles of fig. 5 and fig. 6 , the differences can be seen due to the occurrence of scratches on the surface, which can be contributed to the small hardness of the workpiece. The scratches are also visible on the roughness profile of fig. 7 obtained after the grinding the sample No. 2 . Their formation influenced on the value of $R t$ parameter.

Fig. 8 shows values of the asymmetry coefficient of the roughness profile $R$ sk obtained after individual grinding tests. Negative values of this parameter indicate that the ground surfaces have a high bearing load.

$$
\text { Rsk Number of sample }
$$

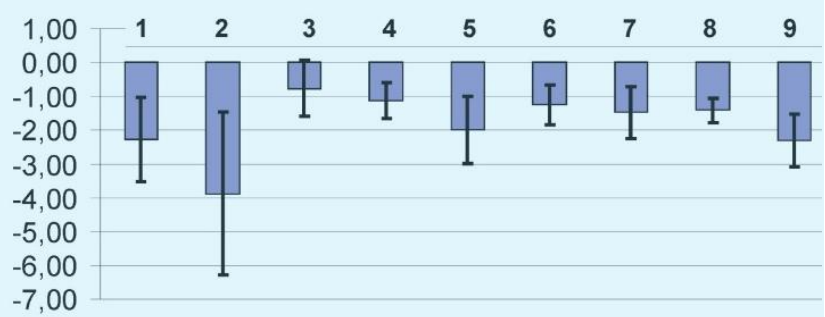

Fig. 8. Average values of the asymmetry coefficient for the roughness profile Rsk after subsequent grinding tests

\section{Conclusions}

Based on the grinding of 1.0562 steel in the softened state, it has been determined that the longitudinal feedrate $v_{\mathrm{ft}}$ has a greater effect on the surface roughness than the grinding depth $a_{e}$. The lowest surface roughness was reported for the grinding parameters No. 5. The smallest values of the $R a$ roughness parameter - in the range of $0.06 \div 0.08 \mu \mathrm{m}$ - appear to be the limiting values that can be achieved under the accepted conditions of grinding of low hardness objects. Increasing the $v_{\mathrm{ft}}$ speed over $1.8 \mathrm{~m} / \mathrm{min}$ resulted in an increased surface roughness. At the lowest accepted feedrate, the best results were also not obtained.

\section{REFERENCES}

1. Janardhan M. „An integrated evaluation approach for modelling and optimization of surface grinding process parameters”. Materials Today: Proceedings. 2 (2015): pages 1622-1633.

2. Oczoś K.E., Porzycki J. „Szlifowanie: podstawy i technika”. Warszawa: Wydawnictwa Naukowo-Techniczne, 1986.

3. Puertoa P. et al. „Evolution of surface roughness in grinding and its relationship with the dressing parameters and the radial wear". Procedia Engineering. 63 (2013): pages 174-182.

4. Tyuhta A.V., Vasilenko Y.V., Kozlov A.M. „Ways to enhance environmental flat grinding by improving the technology of the coolant supply". Procedia Engineering. 150 (2016): pages 1073-1080.

5 . Uhlmann $E$. et al. „Influence of rail grinding process parameters on rail surface roughness and surface layer hardness". Wear. 366-367 (2016): pages 287-293.

6 . Zhaohui Deng et al. „Study on the model of high efficiency and low carbon for grinding parameters optimization and its application". Journal of Cleaner Production. 137 (2016): pages 1672-1681. 